\title{
Article
}

\section{Shared mental models and intra-team psychophysiological patterns: A test of the juggling paradigm}

Filho, Edson, Pierini, Davide, Robazza, Claudio, Tenenbaum, Gershon and Bertollo, Maurizio

Available at http://clok.uclan.ac.uk/14052/

Filho, Edson ORCID: 0000-0002-8548-4651, Pierini, Davide, Robazza, Claudio, Tenenbaum, Gershon and Bertollo, Maurizio (2016) Shared mental models and intra-team psychophysiological patterns: A test of the juggling paradigm.

Journal of Sports Sciences, 35 (2). pp. 112-123. ISSN 0264-0414

It is advisable to refer to the publisher's version if you intend to cite from the work. http://dx.doi.org/10.1080/02640414.2016.1158413

For more information about UCLan's research in this area go to http://www.uclan.ac.uk/researchgroups/ and search for <name of research Group>.

For information about Research generally at UCLan please go to http://www.uclan.ac.uk/research/

All outputs in CLoK are protected by Intellectual Property Rights law, including Copyright law. Copyright, IPR and Moral Rights for the works on this site are retained by the individual authors and/or other copyright owners. Terms and conditions for use of this material are defined in the policies page.

\section{CLoK}

Central Lancashire online Knowledge www.clok.uclan.ac.uk

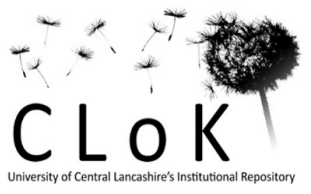


INTRA-TEAM PSYCHOPHYSIOLOGICAL PATTERNS

1

2

3

4

5

7

8

11

12

13 Corresponding Author:

14 Edson Filho

15 University of Central Lancashire

16 School of Psychology

17 Darwin Building, DB114

18 Preston

19 Lancashire, United Kingdom

20 PR1 2HE

21 efilho@uclan.ac.uk

\section{A Test of the Juggling Paradigm}

Edson Filho ${ }^{1}$, Davide Pierini² ${ }^{2}$, Claudio Robazza ${ }^{3}$, Gershon Tenenbaum ${ }^{4}$, \& Maurizio Bertollo ${ }^{3}$

${ }^{1}$ School of Psychology, University of Central Lancashire (UK)

${ }^{2}$ School of Industrial Design, University of Montreal (Canada)

${ }^{3}$ Behavioral Imaging and Neural Dynamics Center, University of Chieti (Italy)

22

23 
INTRA-TEAM PSYCHOPHYSIOLOGICAL PATTERNS

\section{Abstract}

25 We explored implicit coordination mechanisms underlying the conceptual notion of "shared 26 mental models" (SMM) through physiological (i.e., breathing and heart rates) and affective-

27 cognitive (i.e., arousal, pleasantness, attention, self-efficacy, other's efficacy) monitoring of two

28 professional jugglers performing a real-time interactive task of increasing difficulty. There were

29 two experimental conditions: "individual" (i.e., solo task) and "interactive" (i.e., two jugglers

30 established a cooperative interaction by juggling sets of balls with each other). In both

31 conditions, there were two task difficulties: “easy” and "hard”. Descriptive analyses revealed that

32 engaging in a dyadic cooperative motor task (interactive condition) required greater

33 physiological effort (Median Cohen’s $d=2.13$ ) than performing a solo motor task (individual

34 condition) of similar difficulty. Our results indicated a strong positive correlation between the 35 jugglers' heart rate for the easy $(r=.87)$ and hard tasks $(r=.77)$. The relationship between the 36 jugglers’ breathing rate was significant for the easy task $(r=.73)$ but non-significant for the hard 37 task. The findings are interpreted based on research on SMM and Theory of Mind. Practitioners 38 should advance the notion of "shared-regulation" in the context of team coordination through the 39 use of biofeedback training. 
INTRA-TEAM PSYCHOPHYSIOLOGICAL PATTERNS

\section{Shared Mental Models and Intra-Team Psychophysiological Patterns:}

\section{A Test of the Juggling Paradigm}

Since the first use of the term "social neuroscience” in a paper by Cacioppo and Berntson in 1992, there has been minimal, if any, research on cooperative motor tasks based on an interactive, rather than passive, research paradigm (Goldman, 2012; Schilbach et al., 2013). In this context, recent efforts in social cognition have been directed at understanding team coordination, particularly through dynamic research approaches (De Jaegher \& Di Paolo, 2013). Scholars have argued that it is important to study interactive tasks, where information flows bidirectionally between two or more individuals, rather than passive tasks in which information flows unidirectionally from an active to a disengaged subject or system (e.g., avatar; see Schilbach et al., 2013). The study of interactive motor tasks allows one to examine whether and how bio-psycho-social networks, such as autonomic and cognitive-affective-behavioral mimicry, might influence team processes in naturalistic settings (De Jaegher, Di Paolo, \& Gallagher, 2010; Filho, Bertollo, Robazza, \& Comani, 2015a). The present study is an initial attempt to explore team coordination during a real-time interactive task of increasing difficulty.

We subscribed to Eccles and Tenenbaum’s (2004) conceptual framework of team coordination in sports to study coordination during (“in-process”) dyadic juggling. This framework is based on the notion that optimal performance is influenced by the development of shared coordination among teammates. Coordination refers to spatio-temporal synchronized action and effort among teammates and includes (a) explicit coordination, manifested through verbal communication and (b) implicit coordination, exhibited through non-verbal behavior and body responses (Filho \& Tenenbaum, 2012). In bio-neuro-cognitive terms, team coordination is made possible through the development of "shared mental models" (SMM), which consist of 
INTRA-TEAM PSYCHOPHYSIOLOGICAL PATTERNS

common schemas “about team tasks, task context and strategies, team interaction patterns, and teammates’ traits” (Xinwen, Erping, Ying, Dafei, \& Jing, 2006, p. 598).

Although extant research on explicit team coordination exists, few, if any, studies have been conducted on the physiological markers of implicit coordination underlying the conceptual notion of SMM in real-time interactive tasks (Reed et al., 2006; Schilbach et al., 2013). In the present study, we monitored the breathing and heart rate of two professional jugglers participating in an interactive juggling task. Breathing and heart rate patterns have been found to change as a function of increased workload in motor and cognitive tasks (Veltman \& Gaillard, 1998). In particular, breathing rate is an indicator of motor coordination in various tasks (e.g., swallowing; see Martin-Harris, 2006; swimming; see Seifert, Chollet, \& Sanders, 2010).

Similarly, heart rate has been associated with cognitive demands, including attentional control and psychophysiological self-regulation, and the probability of experiencing optimal performance in complex motor tasks (Bertollo et al., 2013).

The study of implicit coordination has its roots in the theory of mind, particularly in its mimicry mechanisms (Goldman, 2012). Mimicry pertains to the synchronization of behavioral and physiological responses. From a behavioral standpoint, there is evidence that individuals are able to "mind-read," empathize, and ultimately mimic facial expressions reflecting a variety of feelings, including physical or emotional pain (Singer et al., 2004). From a physiological standpoint, there is evidence that individuals unconsciously synchronize their somatic responses, such as breathing and heart rates, while cooperating in a task or sharing a social context (Müller \& Lindenberger, 2011). However, there remains a need for studies addressing motor tasks, particularly real-time interactive exchanges, such as dyadic juggling (De Jaegher \& Di Paolo, 2013; Konvalinka \& Roepstorff, 2012; Schilbach et al., 2013). 
INTRA-TEAM PSYCHOPHYSIOLOGICAL PATTERNS

87

Extant research in applied psychology has shown that myriad affective and cognitive states influence team coordination and performance (Eccles \& Tenenbaum, 2004). Accordingly, we also assessed the influence of arousal and pleasantness, attentional strategies, self-efficacy, and other's efficacy beliefs on juggling performance. In this regard, there is empirical evidence suggesting that individuals' affective social behaviors are primarily dependent on their arousal and pleasantness levels (Russell, Weiss, \& Mendelsohn, 1989). For instance, Carney and Colvin (2010) have shown that arousal and pleasantness levels influence myriad social behaviors (e.g., sympathy towards partner; enjoyment during social interaction) among dyads engaged in an interactive task. Furthermore, attentional measures have been used to study joint attention during social interaction as well as performance in motor tasks (Razon, Hutchinson, \& Tenenbaum, 2011). Self-efficacy and other's efficacy are major sources of collective efficacy, which in turn have been found to predict team performance in interactive tasks (Filho, Tenenbaum, \& Yang, 2015b; Magyar, Feltz, \& Simpson, 2004). Finally, we collected the participants’ perceptions of task motivation and task difficulty, given that motivation and difficulty influence the probability of peak performance experiences (i.e., flow-feeling theory; see Kimiecik \& Jackson, 2002).

In summary, the study of real-time interactive tasks is important to understand how team coordination occurs and can be enhanced in naturalistic settings (De Jaegher et al., 2010; Filho et al., 2015a). However, scant research exists on implicit coordination dynamics during highly interactive motor tasks (De Jaegher \& Di Paolo, 2013; Schilbach et al., 2013). Accordingly, we sought to advance research in team coordination through physiological monitoring and affectivecognitive assessment of two professional jugglers performing an interactive juggling task of increasing difficulty. Specifically, we aimed to explore whether the jugglers': (a) physiological and affective-cognitive responses would differ in the individual and interactive conditions, and 
INTRA-TEAM PSYCHOPHYSIOLOGICAL PATTERNS

109 (b) breathing and heart rate patterns would be significantly correlated throughout the juggling

110 tasks, in agreement with the conceptual notion of SMM in general, and implicit coordination in

111 particular. Congruent with previous research in socio-cognition, we expected that: (H1) the

112 jugglers' psychophysiological and affective-cognitive patterns would increase in the interactive

113 condition due to the coordination effort needed for cooperative work in team settings, and (H2)

114 the jugglers' breathing and heart rate patterns would correlate throughout the interactive juggling 115 task.

\section{Methods}

117 Design

We conducted a case study based on a multimodal assessment through the acquisition of

119 objective psychophysiological and subjective self-report data. Our study was based on the 120 recently proposed “juggling paradigm”, which purports that single studies in dyadic juggling

121 offer an epistemologically and methodologically valid platform to advance knowledge on the 122 coupling of peripheral (e.g., breathing and heart rate) and central mechanisms (e.g., hyperbrain 123 analysis) during interactive tasks (for a review see Filho et al., 2015a). Specifically, Filho et al.

124 (2015a) noted that dyadic juggling makes clear that the locus of interest is the "team" rather than 125 the individual. Furthermore, social loafing is unlikely to occur in dyadic juggling as mistakes and 126 lack of effort can be easily and reliably identified.

127 Noteworthy, exploratory research in medicine and social science has relied on case 128 studies to infer functional relationships between two or more conditions (Parker \& Hagan-Burke, 129 2007). Case studies are considered essential in addressing understudied topics in applied 130 psychology (Gage \& Lewis, 2013; Kinugasa, 2013), particularly in the testing of novel

131 conceptual frameworks and research paradigms (see Yin, 2011). Case studies are recommended 
INTRA-TEAM PSYCHOPHYSIOLOGICAL PATTERNS

132 in the study of complex real-life tasks (see Noor, 2008), especially when data collection is

133 complex, costly and time intensive, such as in psychophysiology research (Editorial Nature

134 Neuroscience, 2004; Lane \& Gast, 2014). Case study research is also recommended when

135 participants are highly unique and hard to recruit, such as in the case of highly skilled jugglers.

136 To this extent, it has long been noted that a well-designed nomothetic study targeting socio-

137 cognitive processes should be based on an a priori power analysis based on a nested analysis of

138 variance in its compound structure at the individual and group-level of analysis (Cacioppo \&

139 Berntson, 1992; Raudenbush \& Bryk, 2002). For the present study, this would require a large

140 and unrealistic number of skilled juggling dyads.

141 Participants

142 Prior to taking part in the study, the participants signed an informed consent sheet

143 approved by the authors institutional review board. We purposefully recruited two high-skilled

144 male members of a professional circus school in northeast Canada renowned for preparing

145 world-class performance artists. This sampling approach is consistent with the importance of

146 studying “information rich cases” in order to advance knowledge in expertise development

147 across human domains, including performing arts and sports (Williams \& Ericsson, 2005).

148 Juggler 1 (J1) was 21 years old with 13 years of juggling experience. Juggler 2 (J2) was 21 years

149 old with 12 years of juggling experience. Their juggling schedule involved 10 hours of

150 supervised deliberate practice (effortful, improvement oriented, feedback-based practice) per

151 week. J1 and J2 had never juggled together prior to this study and had no systematic experience

152 in dyadic juggling, congruent with the importance of controlling for historicity effects in socio-

153 cognitive research (see De Jaegher \& Di Paolo, 2013). 
INTRA-TEAM PSYCHOPHYSIOLOGICAL PATTERNS

\section{Juggling Tasks}

$\mathrm{J} 1$ was a specialist in juggling clubs, whereas $\mathrm{J} 2$ was a specialist in diabolo. For the present study, both jugglers were asked to juggle balls in the “cascade juggling pattern,” which represents the most commonly used instrument (balls) and first-learned symmetric pattern (cascade) in juggling (Dancey, 2003). Both jugglers were experts in their respective specialties but J1 had more experience than J2 in juggling with balls. Thus, it is important to note that the juggling tasks were designed taking into account the jugglers’ abilities. Specifically, the juggling tasks were established after three peer debriefing meetings involving the jugglers and their coaches, as well as two pilot tests, including one independent pilot test with two other jugglers. The peer debriefing meetings, based on the notion of cognitive team task analysis (see Klein, 2000), were used to design a reliable and challenging task able to capture skilled performance in an ecologically valid and realistic environment. The peer debriefing meetings involved round table discussions with the jugglers' head coach in order to elicit information about the core components of action proper to cooperative juggling. During the pilot tests, the jugglers were asked to juggle with an increasing number of balls until an "easy” (i.e., minimum number of balls needed for the individual and interactive juggling) and "hard” juggling task (i.e., the maximum number of balls each juggler was able to juggle with) had been identified. Of note, tasks of increased difficulty have been used to identify factors linked to socio-cognitive functioning (i.e., perturbation paradigm; see Massimini, Boly, Casali, Rosanova, \& Tononi, 2009), as well as to identify the mechanisms underlying skilled motor performance (i.e., expert performance approach; see Williams \& Ericsson, 2005). The ideal distance to be kept between the jugglers during the interactive condition was also identified during the pilot trials.

\section{Experimental Conditions}


INTRA-TEAM PSYCHOPHYSIOLOGICAL PATTERNS

We implemented two experimental conditions: “individual” and "interactive” (see Figure 1). In the “individual” condition, which served as control (see Gage \& Lewis, 2013; Schilbach et al., 2013), each juggler performed a solo juggling task. The jugglers performed individually but alongside each other in an effort to control for the presence of another person, thus making it possible to draw comparisons with the interactive condition (Filho et al., 2015a). In the “interactive” condition, the two jugglers established a cooperative interaction by juggling balls with each other. In both conditions, there were two task difficulties: "easy" and "hard".

The jugglers were given five minutes per condition (i.e., individual, interactive) for both the easy and hard task. Based on the pilot trials, and in agreement with their practice habits and performance demands (i.e., juggling acts in circus usually do not exceed five minutes), a five minute trial was deemed appropriate to prevent feelings of fatigue. Therefore, for both conditions and difficulty tasks, the participants were asked to juggle for 10 trials of 30s or for as many trials as needed to complete the five minute time limit.

Individual condition. In the individual condition, the easy task consisted of juggling three balls for both jugglers. The increase in the number of juggling balls from the easy to hard task depended on each juggler's ability. Given differences in their ability to juggle with balls, J1 and J2 did not juggle the same number of balls in the hard task. Rather, J1 juggled with seven balls and J2 juggled with four balls. Although different in absolute terms, the hard task was comparable between subjects in relative terms (as verified during the pilot trials and pre-task peer-debriefing meetings). To this extent, psychophysiology research on cognitive and physical tasks has relied on relative workload indices to compare subjects (see American College of Sports Medicine Guidelines for Exercise Testing and Prescription, 2013). 
INTRA-TEAM PSYCHOPHYSIOLOGICAL PATTERNS

Interactive condition. It was established that a distance of $2.40 \mathrm{~m}$ between the jugglers

201 allowed for optimal amplitude of movement and reliable data collection. The easy task consisted

202 of dyadic juggling with six balls. The hard task consisted of dyadic juggling with eight balls. For

$203 \mathrm{~J}$, the individual/hard task allowed for five degrees of freedom (7 balls for 2 hands), whereas the 204 interactive/hard task allowed for two degrees of freedom (8 balls for 4 hands). For J2, both the 205 individual/hard and interactive/hard tasks allowed for two degrees of freedom (4 balls for 2

206 hands; 8 balls for 4 hands).

\section{Measures}

Task motivation, task difficulty, and number of trials per juggling task served as manipulation checks, assessed through inferential statistical tests, to compare the two

210 experimental conditions. Objective physiological data consisted of the participants’ breathing 211 and heart rate patterns. Subjective affective-cognitive measures included data on participants 212 reported levels of arousal, pleasantness, attention, self-efficacy, and other's efficacy. All self213 report data were collected for both conditions, following the completion of the easy and hard 214 task. The participants' self-reports were collected through single-item measures, which are 215 considered reliable and less intrusive than multi-item measures while collecting data during real216 time interactions (Kamata, Tenenbaum, \& Hanin, 2002).

\section{Manipulation checks: Task motivation, task difficulty, and number of trials/time}

218 per trial. A single-item scale, ranging from 0 (not at all) to 10 (very much), was used to measure 219 perceived motivation to complete the juggling tasks. The participants were instructed to report on 220 the following item: “To what degree did you feel motivated to complete this juggling task?” To 221 measure task difficulty, the participants were asked to respond to the following statement: "How 222 difficult was it for you to complete this juggling task?” Participants rated the item on a scale 
INTRA-TEAM PSYCHOPHYSIOLOGICAL PATTERNS

223 ranging from 0 (not at all difficult) to 10 (very difficult). Finally, we recorded how many trials

224 the jugglers needed to complete the 5min task in both conditions and the two levels of difficulty.

225 The chronometers were stopped every time a ball was dropped to determine the duration of each

226 trial.

227

Physiological recordings: Breathing and heart rate. We used two synchronized

228 FlexComp Infiniti biofeedback systems (Thought Technology Ltd., CA) to continuously record

229 the participants' breathing and heart rates. Specifically, electrocardiogram (ECG) and respiration

230 data were recorded continuously. The ECG sampling rate was $2048 \mathrm{~Hz}$ and the movement

231 associated with respiration was recorded at $256 \mathrm{~Hz}$. Breathing rates (breaths per minute) were

232 recorded using a respiration sensor belt placed around the jugglers' abdomen at the level of the

233 lower ribs. Heart rate data (beats per minute) were captured using three gelled self-adhesive

234 electrodes placed below the right clavicle, left clavicle, and left pectoral muscle below the

235 xiphoid process (lower part of the sternum). Physiological data for the two jugglers in the

236 interactive condition were collected using two Thought Technology hardware and software

237 systems. The two systems were connected by a series of Bayonet Neil-Concelman (to time-lock

238 the data of both jugglers) and synchronized with a JVC - Everio Digital Camcorder via a TT-AV

239 Sync Sensor with a visual trigger delay time $<200 \mu$ s.

240 Arousal and pleasantness levels. A modified version of the Affect Grid (Russell et al.,

241 1989) was used to measure affect throughout the juggling tasks. There is extensive

242 psychometrical evidence suggesting that core affect is a byproduct of pleasure-displeasure and

243 degree of arousal (for a review see Russell et al., 1989). The participants were asked to rate their

244 arousal levels ranging from 1 (sleepiness) to 9 (high arousal) and perceptions of pleasure ranging

245 from 1 (unpleasant) to 9 (pleasant). 
INTRA-TEAM PSYCHOPHYSIOLOGICAL PATTERNS

Attention. Dissociation (e.g., external thoughts about the environment; daydreaming) and association (e.g., internal thoughts; juggling technique) attentional focus were measured throughout the juggling tasks. Attention was measured on a 10-point scale ranging from 0 (pure dissociation) to 10 (pure association) akin to extant research in sport and exercise psychology (for a review see Razon et al., 2011).

Efficacy beliefs: Self-efficacy and other's efficacy. The participants were asked to rate their efficacy beliefs in themselves and their partner using a Likert-type scale ranging from 0 to 100, with increments of 10 and three verbal anchors for 0 (cannot do at all), 50 (moderately can do), and 100 (highly certainly can do). These single-item measurements were designed in agreement with Bandura's (2006) guidelines for constructing efficacy scales. The probe for selfefficacy was: "How confident are you in your ability to successfully juggle with three/four/seven balls?” The probe for other's efficacy collected for the interactive condition only was: "How confident are you that your juggling partner is able to successfully juggle with six/eight balls?”

\section{Procedures}

Data collection took place in a spacious athletic gymnasium and consisted of (a) baseline assessment, (b) familiarization trials, and (c) experimental protocol for individual and interactive conditions. The first part of the baseline assessment involved the jugglers standing quietly until their physiological signals showed a stable pattern within normal ranges. The second part of the baseline assessment involved recording breathing rate and heart rate for five minutes. After the baseline assessment, the jugglers were given a series of familiarization trials until they reported feeling comfortable with the biofeedback apparatus.

The experimental protocol commenced with the individual condition. For the easy task, both J1 and J2 juggled with three balls. For the hard task, J1 juggled with seven balls and J2 
INTRA-TEAM PSYCHOPHYSIOLOGICAL PATTERNS

269 juggled with four balls, in agreement with their individual maximum ability. The interactive

270 condition followed and involved J1 and J2 juggling together sets of balls at a distance of $1.20 \mathrm{~m}$

271 from each other. The jugglers started a dyadic juggling combination with six balls (easy task),

272 and then progressed to eight balls (hard task).

273 In both the individual and interactive conditions, the jugglers were given a minimum rest

274 period of five minutes between the easy and hard tasks to minimize fatigue. There was not a pre-

275 established time limit for the rest intervals. Rather, the jugglers were able to decide when to

276 restart the task. This rationale was based on the contemporary notion that fatigue is ultimately

277 voluntarily regulated (see Marcora \& Staiano, 2010).

278

The researchers monitored data collection and kept the time for each condition

279 throughout the experimental protocol to assess how long, on average, the jugglers were able to

280 juggle without dropping any balls. Specifically, two researchers monitored the physiological

281 apparatus to ensure reliable data collection. Two other researchers collected the participants'

282 subjective self-report data for the easy and hard juggling tasks for both experimental conditions.

283 Specifically, arousal, pleasantness and attention data were collected prior to and after the easy

284 and hard tasks for both experimental conditions to assess how these variables differ from resting

285 states (baseline) and according to different factors (easy and hard tasks; individual and

286 interactive conditions), akin to previous research in sport psychology (Basevitch et al., 2011;

287 Bertollo et al., 2015; Razon, Mandler, Arsal, Tokac, \& Tenenbaum, 2014). Efficacy data were

288 not collected during baseline as efficacy information should be related to a specific performance

289 task (Bandura, 2006). It took approximately two hours to complete the experimental protocol.

290 Data Analysis 
INTRA-TEAM PSYCHOPHYSIOLOGICAL PATTERNS

291

292

293

294

295

296

297

298

299

300

301

302

303

304

305

306

307

308

309

310

311

312

313

The first step in our data analysis consisted of identifying the total number of trials needed to complete the juggling tasks, as well as the jugglers' breathing and heart rate patterns associated with each trial. We then averaged the data with respect to our factors of interest, which consisted of the two conditions and two task difficulties.

Trial identification. The first and second author viewed the video recording of the study to identify the total number of trials in each $5 \mathrm{~min}$ task (easy and hard) for both conditions. A trial started when the jugglers threw the first ball in the air and ended when a ball was dropped. We only included trials longer than 10s in our final analysis to allow for reliable signal processing of the physiological data. With psychophysiological data, the signal-to-noise-ratio is less reliable in short epochs (see Weishaupt, Kochli, \& Marincek, 2006). Furthermore, it is unlikely that someone can juggle three or more balls by chance for a period of 10 or more seconds (Dancey, 2003). The jugglers breathing and heart rate recordings were visually inspected for each valid trial. Any segments containing artifacts caused by movements or electrical interference from muscle contraction were eliminated from subsequent analysis. Finally, the jugglers' breathing and heart rate mean and standard deviation values were calculated from the artifact-free recordings using the Biograph Infinity software.

Variables of interest. Physiological data for each trial were identified, using the analysis feature of the Thought Technology Biograph Infiniti Software, and averaged for each condition and task difficulty. The affective-cognitive data were also analyzed in regards to each condition and task difficulty. Noteworthy, we adhered to current guidelines on single-case research by using both visual (i.e., line graphs) and descriptive (i.e., effect size computations) methods of analysis (see Gage \& Lewis, 2013; Kinugasa, 2013; Lane \& Gast, 2014; Tate, Perdices, McDonald, Togher, \& Rosenkoetter, 2014). Wide-ranging line graphs are the primary form of 
INTRA-TEAM PSYCHOPHYSIOLOGICAL PATTERNS

314 displaying results in case studies (Gage \& Lewis, 2013; Lane \& Gast, 2014; Tate et al., 2014).

315 Accordingly, we prepared our graphs to display information on level (means), variability (point-

316 to-point series) and trend (i.e., changes over time) for both conditions.

317 We also computed effect sizes (ES), which are considered more appropriate than

318 hypothesis testing in single-case research (Kinugasa, 2013). Specifically, we computed Cohen's

$319 d$ effect size to assess whether jugglers’ physiological response (i.e., breathing and heart rates)

320 changed from the individual to interactive condition (i.e., H1). We computed $r$ family ES to

321 assess the degree of association between the jugglers' heart rate and breathing responses in the

322 interactive condition (i.e., H2). Further, we computed Cohen’s Percent of Nonoverlapping Data

323 (CPND), a widely supported technique in comparative case-study analysis, which expresses the

324 percentage of underlap between two data sets (see Parker \& Hagan-Burke, 2007). Inferential

325 statistics (T-tests and ANOVAs) were used to test our experimental manipulation, with respect to

326 number of trials/time per trial, and time on trial, and physiological data.

\section{Results}

First, we present information supporting our experimental manipulation. We then provide

329 visual and descriptive data exploring $\mathrm{H} 1$ and $\mathrm{H} 2$. In Tables 1 and 2, we present descriptive

330 statistics for the individual and interactive conditions. In Figures 2, 3 and 4 we visually compare

331 J1 and J2 for both physiological and affective-cognitive data across conditions and task

332 difficulties.

\section{Manipulation Checks}

334 Task motivation. On a 10-point Likert-type scale, motivation scores for both conditions

335 and task difficulties were above $8(\mathrm{~J} 1, M=9, S D=1.41 ; \mathrm{J} 2, M=9.5, S D=.71)$. Therefore, the

336 jugglers were motivated to complete the juggling tasks. 
INTRA-TEAM PSYCHOPHYSIOLOGICAL PATTERNS

Task difficulty. In the individual condition, J1 and J2 reported low scores of difficulty for the easy task (scores $\leq 2$ ) and high scores for the hard task (scores $\geq 8$ ). In the interactive condition, both jugglers reported low scores of difficulty for the easy task (scores $=1$ ). The hard task was perceived as slightly more difficult than the easy task by J1 (score = 2). J2 perceived the hard task as more difficult than the easy task (score $=5$ ). Thus, for both conditions, J1 and J2's perceived assessment of task difficulty was higher for the hard task, with respect to the easy task. $\mathrm{J} 2$ perceived the interactive hard task as more difficulty than J1 did, adding to the notion that J1 was the more skilled juggler. To verify the task difficulty levels and thus our experimental manipulation from an objective standpoint, we contrasted the number of trials/time per trial for the two different tasks according to the individual and interactive conditions.

Number of trials/time per trial. In the individual easy task, both jugglers were able to complete 10 trials of 30s without any mistakes. In the individual hard task, J1 used 21 trials (9 valid) and $\mathrm{J} 2$ used 15 trials (10 valid). In the interactive condition, the jugglers used 10 trials in the easy condition (9 valid) and 26 trials in the hard condition (7 valid). Overall, from the easy to the hard tasks, there was an increase in the number of trials associated with a decrease in time per trial. In the individual condition, time per trial differed between the easy $(M=30 \mathrm{sec})$ and hard tasks $(M=13.56 \mathrm{sec}, S D=2.61)$ for $\mathrm{J} 1, t(7)=17.81, p=.001$. Furthermore, time per trial also differed for $\mathrm{J} 2$ between the easy $(M=30 \mathrm{sec})$ and hard tasks $(M=14.05 \mathrm{sec}, S D=6.08)$, $t(9)=8.29, p=.01$. In the interactive condition, time per trial also differed, $t(6)=6.46, p=.001$, between the easy $(M=28.17 \mathrm{sec}, S D=2.98)$ and hard tasks $(M=13.43 \mathrm{sec}, S D=3.46)$. A repeated measures (RM) ANOVA was used to compare the jugglers' time per trial (i.e., how long they were able to keep the balls in the air) for the easy and hard tasks across the two experimental conditions. The results revealed a non-significant effect for the three easy tasks 
INTRA-TEAM PSYCHOPHYSIOLOGICAL PATTERNS

360 (easy task for J1, J2, and interactive condition), $F(2,8)=2.70, p=.14$, and for the three hard

361 tasks (hard task for J1, J2, and interactive condition), $F(2,5)=.71, p=.54$. Thus, there was

362 reliability in comparing difficulty levels for the jugglers in both conditions.

Time on trial and physiological data. J1 and J2's time on trial and physiological data

were contrasted for the first half ( 0 to $2.5 \mathrm{~min}$ ) and second half (2.5 to $5.0 \mathrm{~min}$ ) of the $5 \mathrm{~min}$ trials

by condition and task difficulty. In the individual condition, non-significant effects were revealed

366 for both the easy and hard tasks on time on trial. However, differences were observed in the

367 individual/hard task for $\mathrm{J} 1$ on both breathing rate, $F(1,3)=43.61, p=.001$, and heart rate, $F(1$,

$3683)=40.90, p=.001$. Furthermore, differences were observed for $\mathrm{J} 2$ on the individual/hard task

369 for both breathing rate, $F(1,4)=49.85, p=.002$, and heart rate, $F(1,4)=14.96, p=.02$. In the

370 interactive condition, no statistically significant differences were found between the first and

371 second halves.

372 Individual Condition

373 Physiological recordings: Breathing and heart rate. Breathing and heart rates were

374 higher when performing the hard task for both jugglers (Figure 2), attesting that the hard task

375 required greater physiological activation. J1's breathing rate, $t(16)=11.57, p=.01$, and heart

376 rate, $t(16)=7.50, p=.01$, were significantly higher for the hard task compared with J2 (Figure

377 4). J1's breathing and heart rates were not significant for the easy task ( $r \mathrm{ES}=.56, p=.10, n=$

$37810)$ and strongly correlated for the hard task ( $r \mathrm{ES}=.87, p=.01, n=9$ ). Similar to J1, J2's

379 breathing and heart rates were moderately correlated and not significant for the easy task ( $r$ ES =

$380.60, p=.07, n=10)$ and strongly correlated for the hard task $(r \mathrm{ES}=.74, p=.02, n=10)$. Thus,

381 there was a higher intra-physiological overlap between breathing rate and heart rate for both

382 jugglers in the hard task. 
INTRA-TEAM PSYCHOPHYSIOLOGICAL PATTERNS

Easy task. Breathing rate for the easy task was lower for both J1 and J2 in the individual condition than in the interactive easy condition. CPND was $85.20 \%$ for $\mathrm{J} 1$ and $91.31 \%$ for J2, suggesting a minimal combined data overlap across the conditions. Furthermore, the 95\% confidence intervals (CI) for the Cohen's $d$ ES computations did not include zero, indicating that estimated differences are a robust statistical effect distinguishable from zero. Heart rate for the easy task was lower for $\mathrm{J} 1$ and $\mathrm{J} 2$ in the individual condition compared to the interactive easy condition. The magnitude of this difference was $83.20 \%$ for $\mathrm{J} 1(d=2.08)$ and $36.11 \%$ for $\mathrm{J} 2(d=$ .65). The CIs for this comparison did not include zero for J1, whereas the CI for J2 did include zero. Thus, it is not possible to affirm with 95\% reliability that J2's heart rate differed in the individual and interactive conditions, in respect to the easy task.

Hard task. Breathing rate for the hard task was noticeably lower for J1 ( $d=-5.04$; CPND $=100 \%)$ and moderately higher for $\mathrm{J} 2(d=.25, \mathrm{CPND}=13.89 \%)$ compared to the interactive hard condition. The CI for this comparison did not include zero for J1. However, the CI for J2 did include zero. Thus, it is not possible to affirm, with 95\% reliability, that J2's breathing rate differed between the individual and interactive conditions, in respect to the hard task. Finally, heart rate for the interactive hard task was lower for both $\mathrm{J} 1(d=-4.46)$ and $\mathrm{J} 2(d=-2.14)$ compared to the respective values recorded during the individual hard task.

Affective-cognitive data. Both jugglers reported that the easy task was less pleasant and required less activation than the hard task (Figure 2, Panels A and B). Both jugglers reported directing their attention more inwards (associative strategy) in the hard task than the baseline assessment and easy task (Figure 2, Panel C). Self-efficacy was lower for both jugglers in the hard task (Figure 2, Panel D).

\section{Interactive Condition}


INTRA-TEAM PSYCHOPHYSIOLOGICAL PATTERNS

Physiological recordings: Breathing and heart rate. J2's breathing rate and heart rate were positively correlated for both the easy $(r$ ES $=.69, p=.04)$ and hard task $(r$ ES $=.77, p=$ .04). Conversely, J1's breathing and heart rate responses were not related for both the easy ( $r$ ES $=-.17, p=.72)$ and hard tasks ( $r$ ES $=.46, p=.30$ ). Hence, J1's heart and breathing responses were not correlated.

Easy task. When correlating J1 and J2's physiological responses for the easy task (see Table 2), we found a strong effect for breathing rate ( $r \mathrm{ES}=.73, p=.03)$ and heart rate ( $r$ ES = $.87, p=.01)$. The CIs for breathing rate and heart rate did not include zero or negative values, thereby indicating that the correlation between J1 and J2's physiological responses did not occur by chance, and is positive in nature. The $\mathrm{CI}$ for breathing rate was wide and thus a firm conclusion on the "true effect" magnitude of this relationship is not warranted. The CI for heart rate indicates that, when juggling together in an easy task, J1 and J2's heart beats were strongly correlated.

Hard task. When correlating J1 and J2's breathing rates for the hard task, we observed a small negative effect (Table 2). Descriptive statistics indicated that J1 and J2 exhibited similar breathing rate mean values ( $\mathrm{J} 1, M=37.43, S D=3.26$; $\mathrm{J} 2, M=35.00, S D=3.83$ ), with an overlap ratio of $87.5 \%$ (i.e., $12.5 \%$ CPND) for the hard task. Although similar in level, J1 and J2's breathing rate did not exhibit the same variability and trend patterns. When correlating J1 and J2's heart rate for the hard task, a strong relationship ( $r$ ES $=0.77, p=.04$ ) was revealed with a positive CI ranging from .04 to .96. Thus, J1 and J2's heart rate overlapped greatly throughout the hard task.

Affective-cognitive data. J1 reported low levels of arousal for both the easy and hard tasks. J2 reported low levels of arousal in the easy task, and moderate arousal levels in the hard 
INTRA-TEAM PSYCHOPHYSIOLOGICAL PATTERNS

429 task (see Figure 2, Panel A). Both jugglers reported relatively low levels of pleasantness for both 430 the easy and hard tasks (see Figure 2, Panel B). J1 reported directing his attention more inwards 431 (associative strategy) in the hard task than in the easy task. J2 reported the same attentional level, 432 primarily dissociative, for both the easy and hard task (see Figure 2, Panel C). J1 reported the 433 highest self-efficacy value possible for both the easy and hard tasks. J2 reported high self434 efficacy for the easy task and moderate efficacy for the hard task (see Figure 2, Panel D). J1 and 435 J2's rates for other's efficacy were 100 of 100 for both task difficulties, and therefore we did not 436 include this finding in the Figures.

\section{Discussion}

We conducted a single-case experimental study aimed at addressing two hypotheses.

439 First, we explored whether two jugglers’ physiological and affective-cognitive responses would 440 differ when comparing solo juggling (individual condition) and dyadic juggling (interactive 441 condition) of increasing difficulty (easy and hard tasks). Secondly, we explored whether the 442 jugglers' breathing and heart rate patterns would be statistically correlated in an easy and hard 443 juggling task, in agreement with the conceptual notion of SMM in general, and implicit 444 coordination in particular. In light of our results, we elaborate on each hypothesis. Hypothesis 1: Comparison between solo and dyadic juggling

For the easy task in the individual and interactive condition, H1 was confirmed for both jugglers. The interactive/easy task required greater physiological activation for both J1 and J2 448 than the individual/easy task. Hence, engaging in a dyadic cooperative motor task likely requires 449 greater physiological effort than performing an individual motor task of similar difficulty. This 450 increase in physiological effort is likely due to one of two reasons. First, the jugglers were less 451 efficient in dyadic juggling, as they had less experience in this interactive task, in comparison to 
INTRA-TEAM PSYCHOPHYSIOLOGICAL PATTERNS

452 solo juggling. More experienced dyadic jugglers would be better able to detect and correct

453 execution mistakes, whereas less experienced dyadic jugglers cannot (for a review see Carter,

454 Braver, Barch, Botvinick, Noll, \& Cohen, 1998; Tenenbaum, 2003). Second, the increase in

455 physiological effort may be a result of the additional energy needed to cope with the

456 coordination requirements associated with cooperative work in team tasks. Both J1 and J2

457 perceived the interactive/easy task as less pleasant than the individual/easy task, and thus

458 coordinating movements with another person in a dyadic task does not appear to be as pleasant

459 as performing an individual mastered motor task. Noteworthy, our findings do not allow for the

460 determination as to whether the increase in physiological expenditure was due to the former or

461 the latter explanation. It is likely that both factors partially explain this finding, akin to the notion

462 of reciprocal determinism in socio-cognitive tasks (Bandura, 1997), which purports that team

463 performance is co-determined by multiple variables on a many-to-many basis. Further research

464 comparing experienced juggling dyads with less experienced dyads is needed to clarify this

465 issue.

466

For the hard task across conditions (individual and interactive), H1 was verified for J2

467 but not for J1. For J1, the interactive/hard task demanded lower physiological activation than the 468 individual/hard task. For J2, no differences in physiological activation were observed when

469 comparing the hard task in the interactive condition with the hard task in the individual

470 condition. These findings can be explained based on the notion of multiscale complexity, which

471 purports that more degrees of freedom are linked to greater task difficulty (Bar-Yam, 2004). In

472 fact, for J1 the hard task in the individual condition was more challenging (7 balls for 2 hands; 5

473 degrees of freedom) than the hard task in the interactive condition ( 8 balls for 4 hands; 2 degrees 
INTRA-TEAM PSYCHOPHYSIOLOGICAL PATTERNS

474 of freedom). For J2, the hard task in both conditions required the same number of degrees of

475 freedom.

It is important to highlight the fact that J1's physiological responses were associated with

477 J2's breathing and heart rate patterns. This result is in line with Theory of Mind, in which

478 individuals’ physiological and affective-cognitive responses tend to overlap in time-locked

479 interactive tasks (Goldman, 2012). This result is also in line with the theoretical notion that there 480 is a "leader" and a "follower" in interactive motor tasks (Konvalinka \& Roepstorff, 2012;

481 Schilbach et al., 2013). Thus, the notion that your team is "only as strong as your weakest link"

482 may hold true for interactive motor tasks, such as juggling and other acrobatics (e.g., dyadic

483 hand-to-hand). Perhaps more importantly, these results suggest that the initiator is likely to be the

484 lower skilled performer, with the follower being the more skilled individual. The better juggler

485 did not experience cognitive overload in the interactive/hard task, and thus he was able to adapt

486 to the less skilled juggler. To this extent, extant empirical evidence suggests that cognitive

487 flexibility allows highly skilled performers to anticipate and adapt to their teammates actions

488 during real-time tasks (Tenenbaum, Basevitch, Gershgoren, \& Filho, 2013).

489 Hypothesis 2: Intra-team psychophysiological and affective-cognitive responses

490 Our results showed a strong positive correlation (i.e., < .70) between the jugglers’ heart

491 rate responses for both the interactive/easy and interactive/hard tasks. Breathing rate for J1 and

492 J2 were also strongly correlated for the interactive/easy task but there was no reliable effect

493 between the jugglers' breathing rates for the interactive/hard task. Three theoretical implications

494 stem from these findings. First, these results offer empirical evidence supporting the theoretical

495 notion that the coupling of physiological mechanisms, such as the positive correlation of heart

496 rate and breathing responses, likely reflects team coordination in interactive motor tasks (Filho et 
INTRA-TEAM PSYCHOPHYSIOLOGICAL PATTERNS

497 al., 2015a). Secondly, the ability to successfully coordinate physiological responses is likely

498 moderated by task difficulty, reinforcing the importance of task analysis in the study of socio-

499 cognition (Klein, 2000; Massimini et al., 2009; Williams \& Ericsson, 2005). In other words,

500 individuals may be more likely to have similar frequency of physiological responses under lower

501 task difficulties and effort demands. Third, the fact that the jugglers' breathing rates did not

502 correlate for the hard task suggests that, although related, breathing rate and heart rate may be

503 indicative of different physiological demands under pressure (i.e., varying degrees of task

504 complexity). Specifically, heart rate has been primarily linked to cognitive load (Veltman \&

505 Gaillard, 1998), whereas breathing rate has been associated with motor coordination (Martin-

506 Harris, 2006). In the interactive/hard task, J2 faced difficulties coordinating his motor responses

507 (probably due to cognitive overload), forcing J1 to compensate for any potential mistake from J2.

508 Therefore, in addition to establishing SMM, evidenced through the coordination of explicit and

509 implicit mechanisms, teammates may also need to develop complementary mental models to

510 achieve optimal performance (Filho et al., 2015a).

511 It is noteworthy that $\mathrm{J} 1$ and $\mathrm{J} 2$ reported the same arousal levels in the interactive/easy

512 task, where a strong correlation of breathing and heart rate responses was observed. However, in

513 the interactive/hard task, J1 reported higher arousal levels than J2, likely because he needed to be

514 more vigilant to adapt to his less skilled partner. Again, these findings corroborate theory of

515 mind assumptions in which social interaction in a naturalistic task is made possible by one's

516 ability to attribute and mimic the mental states of others (see Goldman, 2012; Singer et al.,

517 2004). J1's attentional rates support the notion that harder tasks require greater associative focus

518 (Razon et al., 2011). Conversely, J2 was “frozen” in the same attentional mode, perhaps unable 
INTRA-TEAM PSYCHOPHYSIOLOGICAL PATTERNS

519 to display attentional flexibility under pressure, as is the case for less skilled individuals under

520 increasing pressure (Bertollo et al., 2013; Tenenbaum et al., 2013).

521 Furthermore, J1's efficacy belief scores were higher than J2 for both the interactive/easy

522 and interactive/hard tasks, adding to the evidence that J1 was the more skilled ball juggler.

523 Finally, both jugglers reported the maximum possible score for “others' efficacy”. Although the

524 jugglers’ responses were collected confidentially and in accordance with Bandura’s (2006)

525 guidelines for measuring efficacy beliefs, it is likely that they refrained from reporting negatively

526 on their partner's ability. Future studies should consider cooperative partners with no previous

527 interactions, or larger groups for greater data variability, to better gauge the effect of others

528 efficacy in explaining team coordination. Additional limitations, avenues for future research, and

529 applied implications are discussed next.

Limitations and Future Research Avenues

Our study has limitations that we address to better orient future research in dyadic

532 coordination in sports, particularly studies using interactive research paradigms. First,

533 generalizability power is limited in case studies. Accordingly, future studies should focus on

534 small-n studies (i.e., multi-case studies) to allow for greater inter-subject validation (Noor,

535 2008). For instance, small-n rather than single-case studies would allow for controlling of

536 potential order and learning effects.

Second, the individual/hard task required maximum effort from both jugglers, especially

538 during the second half of the five minute trial. The interactive/hard task was likely limited by

539 J2's ability and was likely not challenging enough to J1. In other words, the individual/hard task

540 equaled a maximum test for each individual, while the interactive/hard condition was, by

541 definition, a byproduct (not necessarily linear) of each juggler's ability. Notwithstanding, the 
INTRA-TEAM PSYCHOPHYSIOLOGICAL PATTERNS

542 interactive/hard task was still very challenging for the dyad as a unit and was comparable in

543 difficulty level to the individual hard/task, as verified by the objective data of number of

544 trials/time per trial. The measurement of perceived feelings of exertion and fatigue, through the

545 use of well-established measures such as the Borg Scale of Perceived Exertion (see Borg, 2001),

546 would have strengthened our ability to compare the easy and hard tasks across conditions.

547 Overall, future studies should continue to explore how individual ability influences intra-team

548 psychophysiological dynamics in dyadic teams. In fact, in the "real world" performers' abilities

549 vary greatly within teams, and coaches and practitioners have to find solutions to optimize

550 coordination among teammates with different skill levels and bio-psycho-social profiles (Filho \&

551 Tenenbaum, 2012). Furthermore, important developments about group dynamics and team

552 processes (e.g., Kohler effect) have originated from studies examining individuals of varying 553 skills levels.

Despite the aforementioned limitations, our study is one of the very first to address

555 psychophysiological coupling in a cooperative real-time motor task. The "juggling paradigm"

556 tested herein may help to answer many of the questions raised on cooperative motor

557 coordination. There is minimal research on this area, and the few that exist involve constrained 558 environments and simple tasks (e.g., finger coordination on fMRI; see De Jaegher \& Di Paolo, 559 2013; Reed et al., 2006; Schilbach et al., 2013). In particular, scholars can alter juggling tasks

560 (cascade vs. shower paradigms; balls vs. clubs), skill levels (experts vs. novices) and difficulty

561 (number of instruments juggled), while monitoring different variables (breathing rate, heart rate,

562 skin conductance, brain waves) through the use of psychophysiological data collection systems, 563 including electroencephalogram and eye-tracking (Filho et al., 2015a). Multi-brain studies,

564 implemented through hyperscanning methodologies, are particularly warranted to identify the 
INTRA-TEAM PSYCHOPHYSIOLOGICAL PATTERNS

565 neural markers of implicit coordination (i.e., topology and efficiency of the functional hyperbrain

566 networks) through high-performance neuroimaging analyses (see Babiloni, \& Astolfi, 2014;

567 Filho et al., 2015a). Finally, studies advancing the concept of shared and complementary mental

568 models in exercise settings are welcomed. Scholars could examine whether and how

569 physiological and cognitive-affective-behavioral mirroring happens in group exercise (e.g.,

570 running partners).

\section{Conclusions and Applied Implications}

572 Our first hypothesis was only partially supported as one of the jugglers exhibited higher

573 psychophysiological activation during the individual hard task, rather than in the interactive hard

574 task, as we had predicted. Therefore, it remains to be determined whether the increase of

575 psychophysiological and affective-cognitive patterns of teammates in interactive motor tasks is

576 due to (1) group-level variability; e.g., the coordination effort needed to complete cooperative

577 tasks, in comparison with individually performed tasks; or (2) individual-level variability; e.g.,

578 skill level and personal experience in cooperative tasks. It is likely that both group- and

579 individual-level variability influences team coordination in interactive tasks (i.e., reciprocal

580 determinism, see Bandura, 1997). As such, practitioners should focus on developing both

581 individuals' skills and team processes (e.g., cohesion, collective efficacy).

582 Our second hypothesis was supported as we showed that implicit coordination of

583 physiological and affective-responses occurred, although this coordination is likely moderated by

584 each individual's skill level and by task difficulty. To this extent, we observed that the more

585 skilled juggler was more likely to "follow" the less skilled juggler. While further research,

586 particularly targeting hyperbrains functional connectivity, must be conducted to determine

587 “leader-follower directionality” in interactive motor tasks (Filho et al., 2015a), this initial result 
INTRA-TEAM PSYCHOPHYSIOLOGICAL PATTERNS

588 has an important applied implication. When proposing cooperative motor tasks, coaches and

589 practitioners should balance challenge and skill of the dyadic team as a whole rather than

590 primarily focusing on the needs of their "star" performer. Instead of having the lower skilled

591 performer adapting to the best player, our results suggests that the best player should be

592 encouraged to adapt to his/her less-skilled teammate.

$593 \quad$ Finally, our findings have the potential to orient the development of group-level bio-

594 neurofeedback interventions. Practitioners could incorporate group-level psychophysiological

595 analysis to identify high and low instances of implicit coordination among teammates in order to

596 orient group-level biofeedback interventions. Applied researchers should advance the notion of

597 "shared-regulation" in the context of team coordination and through the use of biofeedback

598 training, much like we discuss “self-regulation” in the context of individually performed tasks.

599

600 
INTRA-TEAM PSYCHOPHYSIOLOGICAL PATTERNS

601

602

603

604

605

606

607

608

609

610

611

612

613

614

615

616

617

618

619

620

621

622

623
References

American College of Sports Medicine Guidelines for Exercise Testing and Prescription. (2013). ACSM's guidelines for exercise testing and prescriptions. Philadelphia, PA: LLW Publisher.

Babiloni, F., \& Astolfi, L. (2014). Social neuroscience and hyperscanning techniques: past, present and future. Neuroscience \& Biobehavioral Reviews, 44, 76-93. doi:10.1016/j.neubiorev.2012.07.006

Bandura, A. (1997). Self-efficacy: The exercise of control. New York, NY: W. H. Freeman.

Bandura, A. (2006). Guide for constructing self-efficacy scales. In F. Pajares \& T. Urdan (Eds.), Self-efficacy beliefs of adolescents (Vol. 5, pp. 307-337). Greenwich, CT: Information Age Publishing.

Bar-Yam, Y. (2004). Multiscale complexity/entropy. Advances in Complex Systems, 7, 47-63.

Basevitch, I., Thompson, B., Braun, R., Razon, S., Arsal, G., Tokac, U., Filho, E., Nascimento, T., \& Tenenbaum, G. (2011). Olfactory effects on attention allocation and perception of exertion. The Sport Psychologist, 25, 144-158.

Bertollo, M., Bortoli, L., Gramaccioni, G., Hanin, Y., Comani, S., \& Robazza, C. (2013). Behavioural and psychophysiological correlates of athletic performance: A test of the multi-action plan model. Applied Psychophysiology and Biofeedback, 38, 91-99. doi:10.1007/s10484-013-9211-z

Bertollo, M., di Fronso, S., Filho, E., Lamberti, V., Ripari, P., Reis, V. M., . . Robazza, C. (2015). To focus or not to focus: Is attention on the core components of action beneficial for cycling performance? The Sport Psychologist, 29, 110-119. doi:10.1123/tsp.20140046 
INTRA-TEAM PSYCHOPHYSIOLOGICAL PATTERNS

624 Borg, G. (2001). Borg’s range model and scales. International Journal of Sport Psychology, 32, $625 \quad 110-126$.

626 Cacioppo, J. T., \& Berntson, G. G. (1992). Social psychological contributions to the decade of 627 the brain: doctrine of multilevel analysis. American Psychology, 47, 1019-1028.

628 doi:10.1037/0003-066X.47.8.1019

629 Carney, D. R., \& Colvin, C. R. (2010). The circumplex structure of affective social behavior. 630 Social Psychological and Personality Science, 1, 73-80. doi:10.1177/1948550609353135

631 Carter, C. S., Braver, T. S., Barch, D. M., Botvinick, M. M., Noll, D., \& Cohen, J. D. (1998). 632 633 Anterior cingulate cortex, error detection, and the online monitoring of performance. Science, 280, 747-749.

634 Dancey, C. (2003). The Encyclopedia of Ball Juggling. United Kingdom: Butterfingers. 635 De Jaegher, H., \& Di Paolo, E. (2013). Enactivism is not interactionism. Frontiers in Human 636 Neuroscience, 6, 1-2. doi:10.3389/fnhum.2012.00345

637 De Jaegher, H., Di Paolo, E., \& Gallagher, S. (2010). Can social interaction constitute social 638 cognition? Trends in Cognitive Sciences, 14, 441-447. doi:10.1016/j.tics.2010.06.009

639 Eccles, D. W., \& Tenenbaum, G. (2004). Why an expert team is more than a team of experts: A 640 social-cognitive conceptualization of team coordination and communication in sport. Journal of Sport and Exercise Psychology, 26, 542-560.

642 Editorial (2004). When once is enough. Nature Neuroscience, 7, 93. doi:10.1038/nn0204-93

643 Filho, E., Bertollo, M., Robazza, C., \& Comani, S. (2015a). The juggling paradigm: A novel 644 social neuroscience approach to identify neuropsychophysiological markers of team 645 mental models. Frontiers in Psychology, 6. doi:10.3389/fpsyg.2015.00799 
INTRA-TEAM PSYCHOPHYSIOLOGICAL PATTERNS

646 Filho, E., Tenenbaum, G., \& Yang, Y. (2015b). Cohesion, team mental models, and collective

647

648

649

650

651

652

653

654

655

656

657

658

659

660

661

662

663

664

665

666 efficacy: Towards an integrated framework of team dynamics in sport. Journal of Sports Sciences, 33, 641-653. doi:10.1080/02640414.2014.957714

Filho, E., \& Tenenbaum, G. (2012). Team mental models in sports: An overview. In R. Schinke (Ed.), Athletic insight's writings in sport psychology. Hauppauge, NY: Nova Science Publishers. Inc.

Gage, N. A., \& Lewis, T. J. (2013). Analysis of effect for single-case design research. Journal of Applied Sport Psychology, 25, 46-60. doi:10.1080/10413200.2012.660673

Goldman, A. I. (2012). Theory of Mind. In E. Margolis, R. Samuels, \& S. Stich. (Eds.), Oxford Handbook of Philosophy and Cognitive Science. Oxford University Press.

Kamata, A., Tenenbaum, G., \& Hanin, Y. L. (2002). Individual Zone of Optimal Functioning (IZOF): A probabilistic estimation. Journal of Sport and Exercise Psychology, 24, 189208.

Kimiecik, J. C., \& Jackson, S. A. (2002). Optimal experience in sport: A flow perspective. In T. S. Horn (Ed.), Advances in sport psychology (2nd ed., pp. 501-527). Champaign, IL: Human Kinetics.

Kinugasa, T. (2013). The application of single-case research designs to study elite athletes’ conditioning: An update. Journal of Applied Sport Psychology, 25, 157-166. doi:10.1080/10413200.2012.709578

Klein, G. (2000). Cognitive task analysis of teams. In J. M. Schraagen, S. F. Chipman, \& V. L. Shalin (Eds.), Cognitive task analysis (pp. 417-430). Mahwah, NJ: Lawrence Erlbaum. 
INTRA-TEAM PSYCHOPHYSIOLOGICAL PATTERNS

667 Konvalinka, I., \& Roepstorff, A. (2012). The two-brain approach: How can mutually interacting 668 brains teach us something about social interaction? Frontiers in Human Neuroscience, 6 , 669 1-10. doi:10.3389/fnhum.2012.00215

670

671

672

673

674

675

676

677

678

679

680

681

682

683

684

685

686

687

688

689

Lane, J. D., \& Gast, D. L. (2014). Visual analysis in single case experimental design studies: Brief review and guidelines. Neuropsychological Rehabilitation, 24, 445-463. doi:10.1080/09602011.2013.815636

Magyar, T. M., Feltz, D. L., \& Simpson, I. P. (2004). Individual and crew level determinants of collective efficacy in rowing. Journal of Sport \& Exercise Psychology, 26, 136-153.

Marcora, S. M., \& Staiano, W. (2010). The limit to exercise tolerance in humans: Mind over muscle? European Journal of Applied Physiology, 109, 763-770. doi:10.1007/s00421010-1418-6

Martin-Harris, B. (2006). Coordination of respiration and swallowing. Nature: GI Motility Online. doi:10.1038/gimo10

Massimini, M., Boly, M., Casali, A., Rosanova, M., \& Tononi, G. (2009). A perturbational approach for evaluation the brain's capacity for consciousness. Progress in Brain Research, 177, 201-214. doi:10.1016/S0079-6123(09)17714-2

Müller, V., \& Lindenberger, U. (2011). Cardiac and respiratory patterns synchronize between persons during choir singing. PLoS One, 6. doi:10.1371/journal.pone.0024893

Noor, K. B. M. (2008). Case study: A strategic research methodology. American Journal of Applied Sciences, 5, 1602-1604. doi:10.3844/ajassp.2008.1602.1604

Parker, R. I., \& Hagan-Burke, S. (2007). Useful effect size interpretations for single case research. Behavior Therapy, 38, 95-105. doi.org/10.1016/j.beth.2006.05.002

Raudenbush, S. W., \& Bryk, A.S. (2002). Hierarchical linear models (2nd ed.). Thousand Oaks, 
INTRA-TEAM PSYCHOPHYSIOLOGICAL PATTERNS

690

691

692

693

694

695

696

697

698

699

700

701

702

703

704

705

706

707

708

709

710

711

712

CA: Sage Publications.

Razon, S., Hutchinson, J., \& Tenenbaum, G. (2011). Effort perception. In G. Tenenbaum, R. Eklund, \& A. Kamata (Eds.), Measurement in sport and exercise psychology (pp. 265277). Champaign, IL: Human Kinetics.

Razon, S., Mandler, K., Arsal, G., Tokac, U., \& Tenenbaum, G. (2014). Effects of imagery on effort perception and cycling endurance. Journal of Imagery Research in Sport and Physical Activity, 9, 23-38.

Reed, K. B., Peshkin, M., Hartmann, M. J., Patton, J., Vishton, P. M., \& Grabowecky, M. (2006). Haptic cooperation between people, and between people and machines. Intelligent Robots Systems, 2109-2114. doi:10.1109/IROS.2006.282489

Russell, J. A., Weiss, A., \& Mendelsohn, G. A. (1989). Affect grid: A single-item scale of pleasure and arousal. Journal of Personality and Social Psychology, 57, 493-502.

Schilbach, L., Timmermans, B., Reddy, V., Costall, A., Bente, G., Schlicht, T., \& Vogeley, K. (2013). Toward a second-person neuroscience. Behavioral and Brain Sciences, 36, 393462. doi:10.1017/S0140525X12000660

Seifert, L. L., Chollet, D. D., \& Sanders, R. R. (2010). Does breathing disturb coordination in butterfly? International Journal of Sports Medicine, 31, 167-173. doi:10.1055/s-00291243640

Singer, T., Seymour, B., O’Doherty, J., Kaube, H., Dolan, R., \& Frith, C. (2004). Empathy for pain involves the affective but not sensory components of pain. Science, 303, 1157-1162. doi:10.1126/science.1093535

Tate, R. L., Perdices, M., McDonald, S., Togher, L., \& Rosenkoetter, U. (2014). The design, conduct and report of single-case research: Resources to improve the quality of the 
INTRA-TEAM PSYCHOPHYSIOLOGICAL PATTERNS

713

714

715

716

717

718

719

720

721

722

723

724

725

726

727

728

729

730

731

732 neurorehabilitation literature. Neuropsychological Rehabilitation, 24, 315-331. doi:10.1080/09602011.2013.875043

Tenenbaum, G. (2003). Expert athletes: An integrated approach to decision-making. In J. Starkes \& A. Ericsson (Eds.), Expert performance in sports: Advances in research on sport expertise (pp. 192-218). Champaign, IL: Human Kinetics.

Tenenbaum, G., Basevitch, I., Gershgoren, L., \& Filho, E. (2013). Emotions-decision-making in sport: Theoretical conceptualization and experimental evidence. International Journal of Sport and Exercise Psychology, 11, 151-168. doi:10.1080/1612197X.2013.773687

Veltman, J. A., \& Gaillard, A. W. K. (1998). Physiological workload reactions to increasing levels of task difficulty. Ergonomics, 41, 656-669.

Weishaupt, D., Kochli, V. D., \& Marincek, B. (2006). Factors affecting the signal-to-noise ratio. In D. Weishaupt, V. D. Kochli, \& B. Marincek. (Eds.), How does MRI work? (pp. 29-39). Springer-Verlag Berlin Heidelberg.

Williams, A. M., \& Ericsson, K. A. (2005). Perceptual-cognitive expertise in sport: Some considerations when applying the expert performance approach. Human Movement Science, 24, 283-307. doi:10.1016/j.humov.2005.06.002

Xinwen, B., Erping, W., Ying, Z., Dafei, M., \& Jing, R. (2006). Developmental characteristics of two types of shared mental models. Acta Psychologica Sinica, 38, 598-606.

Yin, R. K. (2011). Applications of case study research. London, UK: Sage Publications. 
Table 1

734 Descriptive Statistics for the Jugglers' Breathing Rate (breaths per minute) and Heart Rate (beats per minute) in the Individual and 735 Interactive Conditions by Task Difficulty

\begin{tabular}{|c|c|c|c|c|c|c|c|c|c|c|}
\hline \multirow[t]{2}{*}{ Juggler } & \multicolumn{5}{|c|}{ Individual } & \multicolumn{3}{|c|}{ Interactive } & \multirow[b]{2}{*}{ Cohen's $d$} & \multirow[b]{2}{*}{ CPND } \\
\hline & M & SD & Range & $\begin{array}{c}n \\
\text { trials }^{\dagger}\end{array}$ & M & $\mathrm{SD}$ & Range & $\begin{array}{c}n \\
\text { trials }^{\dagger}\end{array}$ & & \\
\hline \multicolumn{11}{|l|}{$\mathrm{J} 1$} \\
\hline \multicolumn{11}{|c|}{ Breathing Rate } \\
\hline Easy & 23.80 & 3.19 & $19-28$ & 10 & 31.44 & 4.00 & $27-40$ & 9 & $2.13[1.00,3.25]$ & $85.20 \%$ \\
\hline Hard & 56.38 & 4.10 & $51-62$ & 9 & 37.43 & 3.26 & $32-41$ & 7 & $-5.04[-7.05,-3.04]$ & $100 \%$ \\
\hline \multicolumn{11}{|l|}{ Heart Rate } \\
\hline Easy & 87.70 & 5.21 & $76-93$ & 10 & 96.89 & 3.33 & $92-102$ & 9 & 2.08 [0.96, 3.19] & $83.20 \%$ \\
\hline Hard & 153.75 & 14.83 & $125-170$ & 9 & 101.86 & 2.91 & $96-105$ & 7 & $-4.46[-6.24,-2.68]$ & $100 \%$ \\
\hline \multicolumn{11}{|l|}{$\mathrm{J} 2$} \\
\hline \multicolumn{11}{|c|}{ Breathing Rate } \\
\hline Easy & 22.30 & 1.57 & $20-24$ & 10 & 29.00 & 2.91 & $25-36$ & 9 & $2.91[1.62,4.20]$ & $91.31 \%$ \\
\hline Hard & 34.00 & 4.01 & $29-40$ & 10 & 35.00 & 3.83 & $32-43$ & 7 & $0.25[-0.72,1.22]$ & $13.89 \%$ \\
\hline \multicolumn{11}{|l|}{ Heart Rate } \\
\hline Easy & 97.00 & 4.24 & 86-101 & 10 & 99.44 & 3.13 & $94-104$ & 9 & $0.65[-0.27,1.57]$ & $36.11 \%$ \\
\hline Hard & 116.30 & 5.10 & $108-126$ & 10 & 106.29 & 3.95 & $100-111$ & 7 & $-2.14[-3.35,-.94]$ & $85.60 \%$ \\
\hline
\end{tabular}

736

737 Note. ${ }^{\dagger}$ Only valid trials ( $>10 \mathrm{sec}$ ) were considered in the analysis. 
738 Table 2

739 Correlation between J1 and J2 Physiological Responses in the Interactive Condition

740

741

\begin{tabular}{lcc}
\hline Interactive Condition & $r$ ES & CPND \\
\hline Breathing Rate & & \\
Easy & $.73^{*}[.13, .94]$ & $83.4 \%$ \\
Hard & $-.10[-.79, .71]$ & $12.5 \%$ \\
& & \\
Heart Rate & & \\
Easy & $.87^{* *}[.49, .97]$ & $99.4 \%$ \\
Hard & $.77^{*}[.04, .96]$ & $88.0 \%$ \\
\hline${ }^{*} p<.05 ;{ }^{* *} p<.01$ & &
\end{tabular}

742

743

744

745

746

747

748

749

750

751

752

753

754

755 

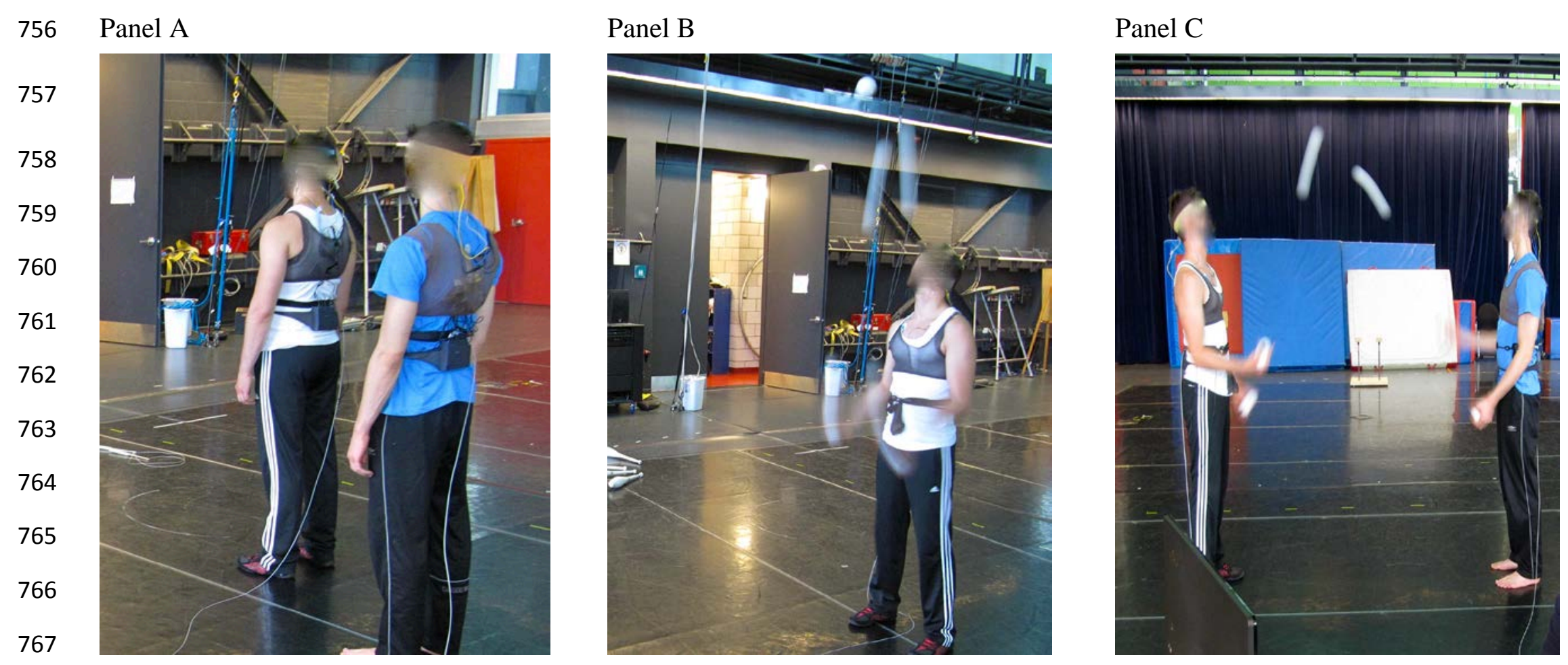

768

769

Figure 1. Baseline assessment (Panel A), individual condition (Panel B), and interactive condition (Panel C). 


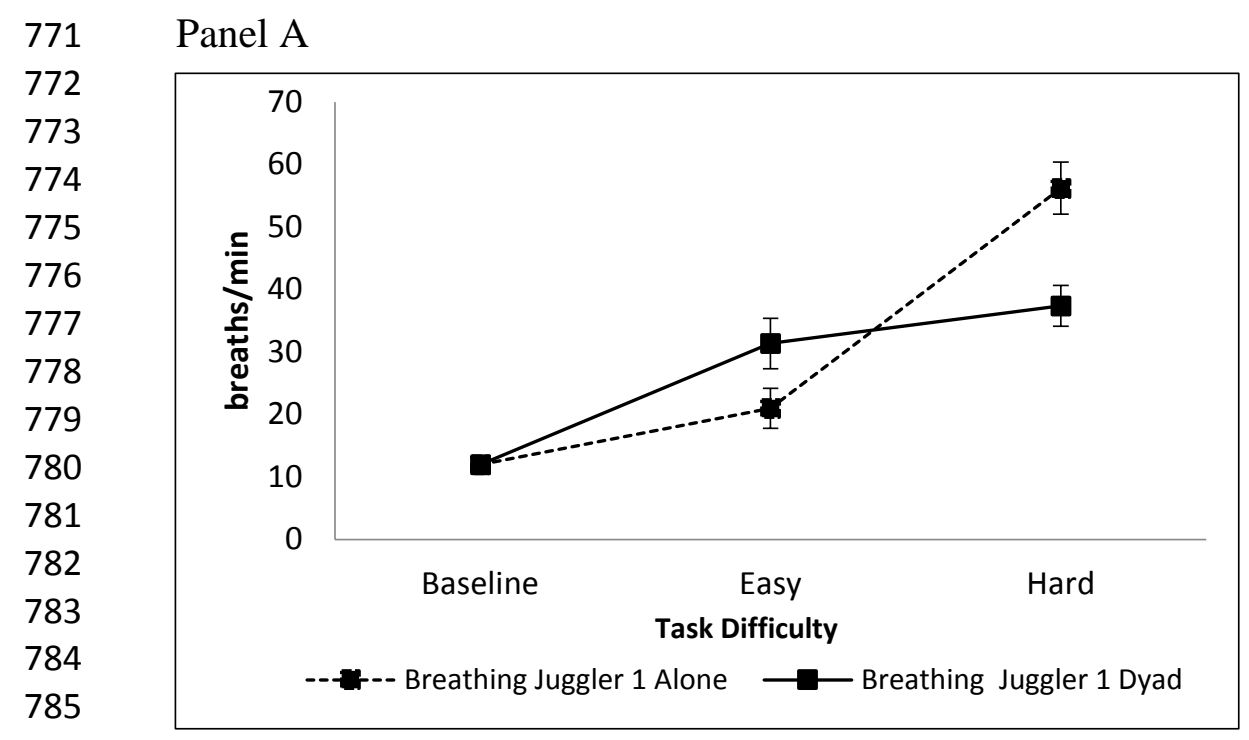

Panel B

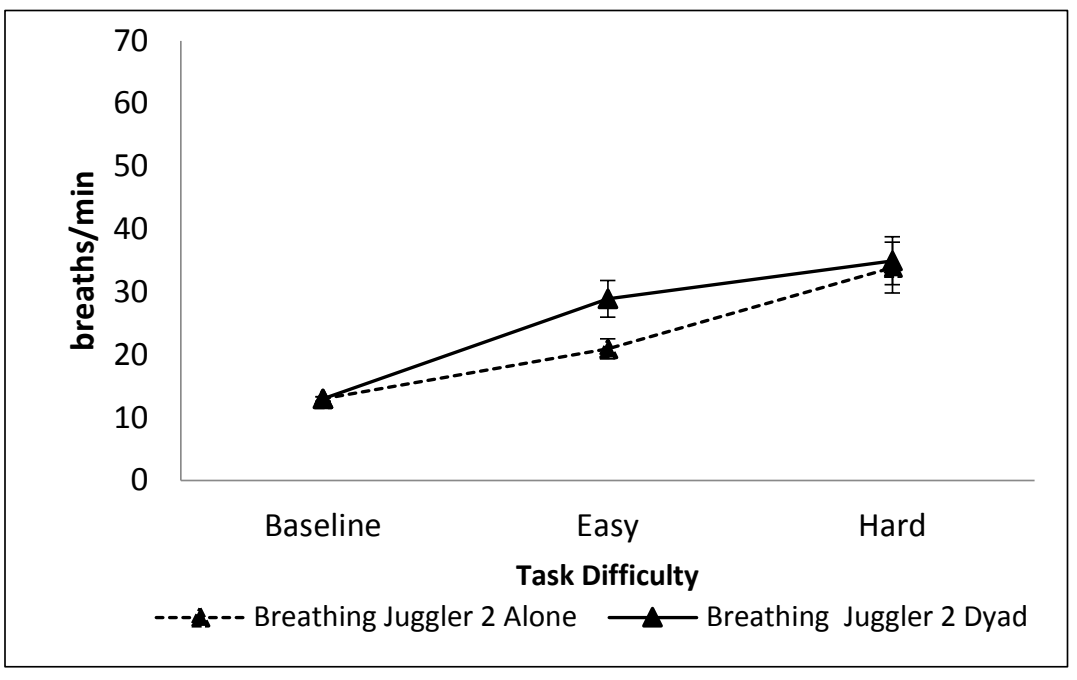

786

\section{Panel C}

Panel D

787

788

789
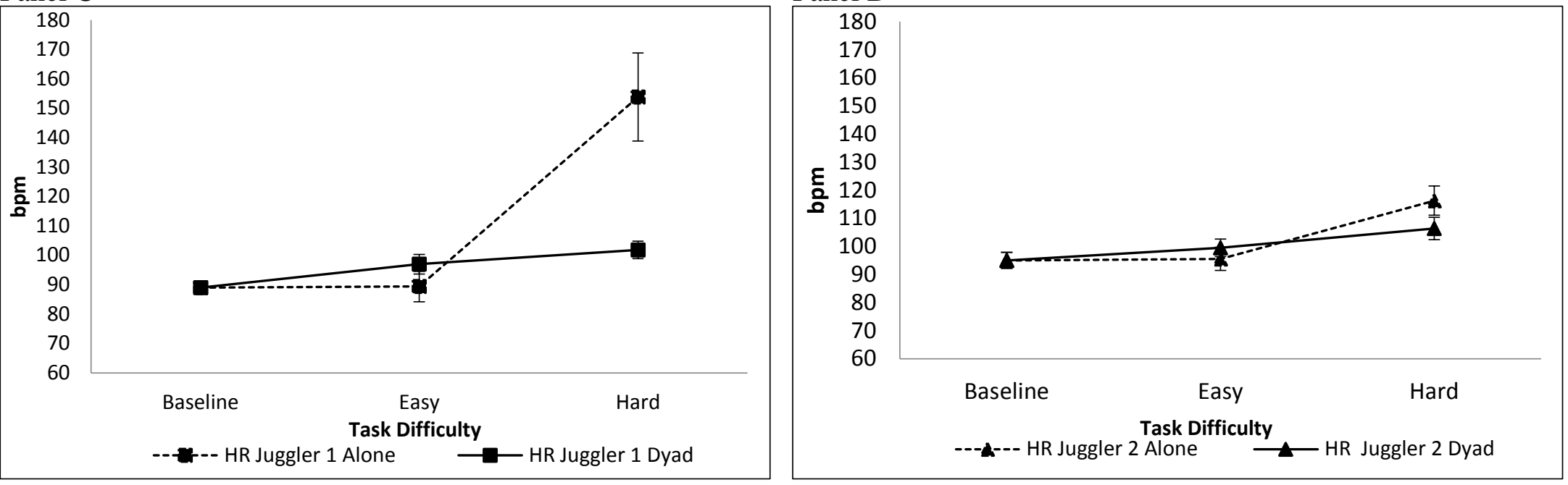

795

796

797

798

Figure 2. Jugglers' breathing rate (breaths per minute; Panel A and B) and heart rate (beats per minute; Panel C and D) by juggling conditions and task difficulties. 
Panel A

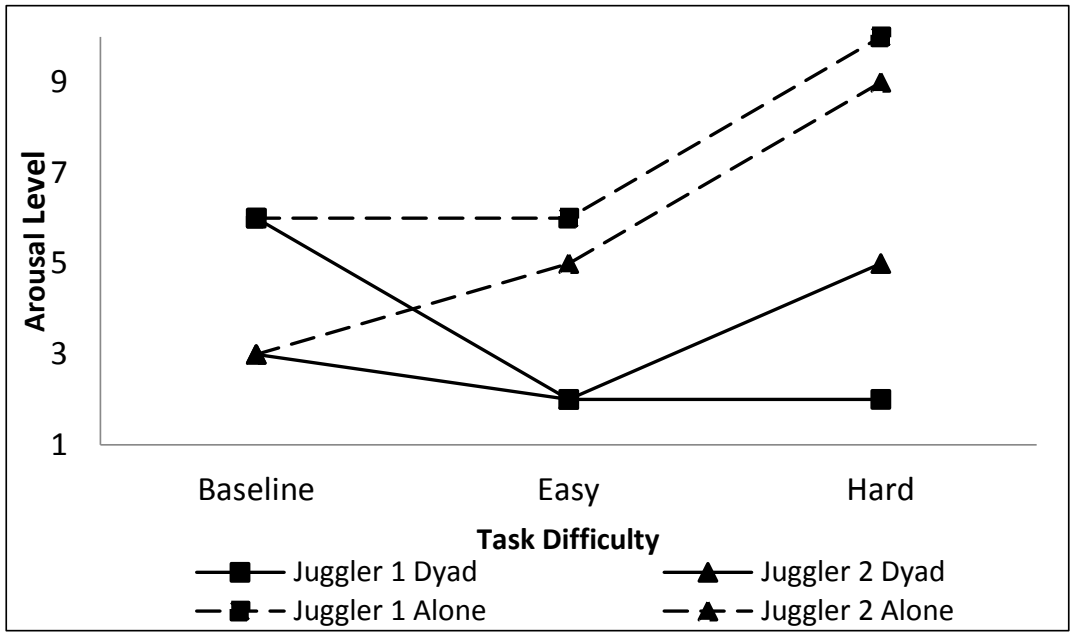

\section{Panel C}

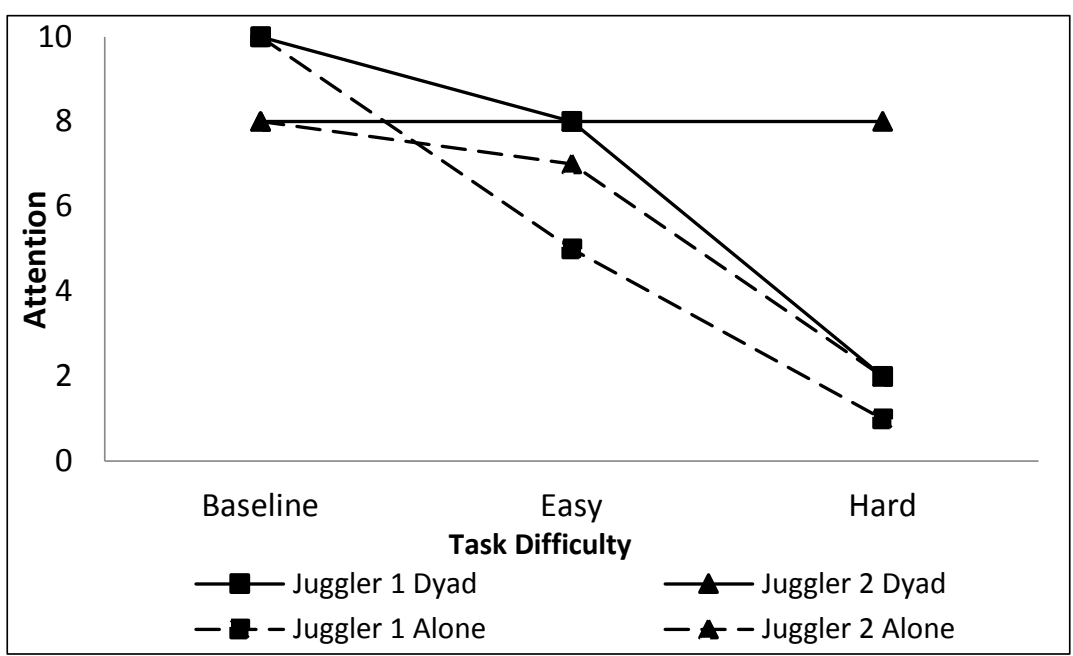

Panel B

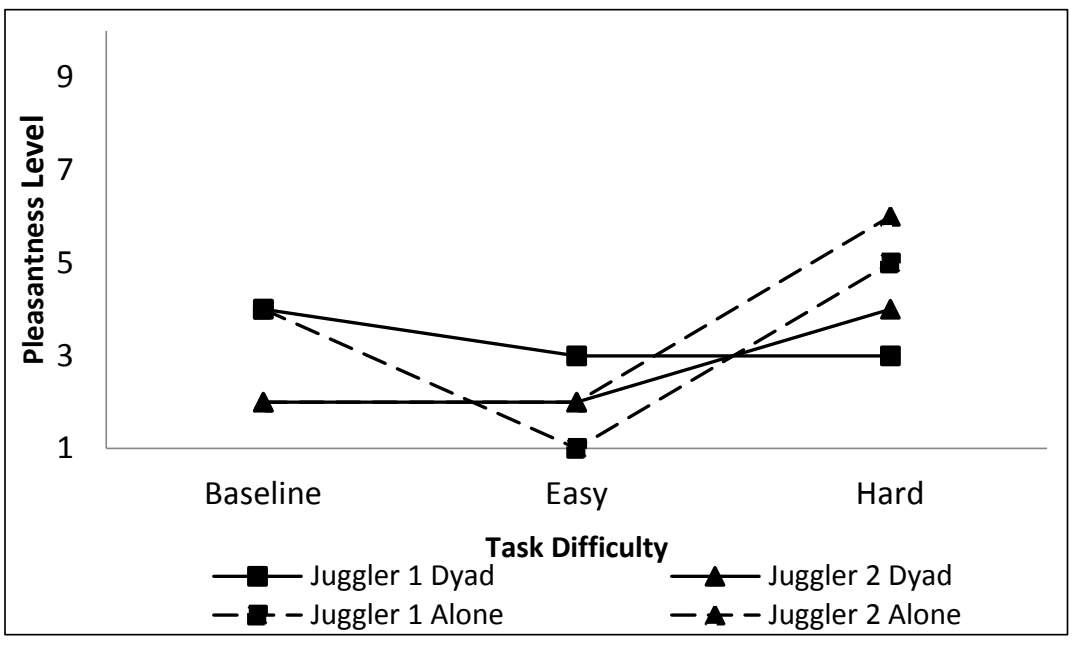

Panel D

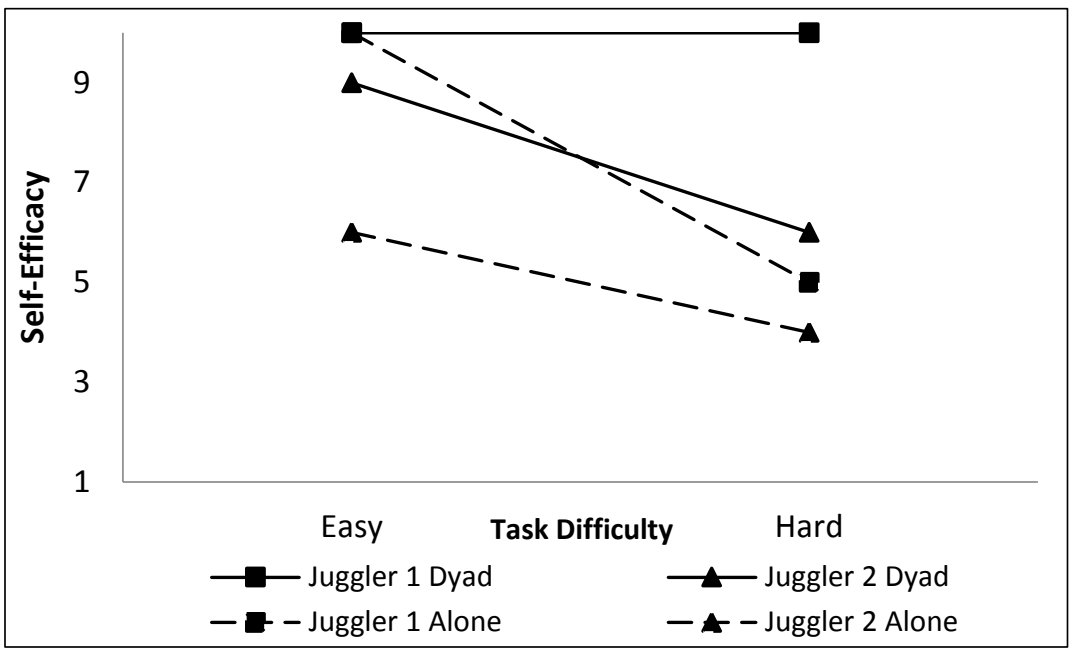

Figure 3. Jugglers' arousal (Panel A), pleasantness (Panel B), attention (Panel C) and self-efficacy levels (Panel D) by juggling conditions and task difficulties. 


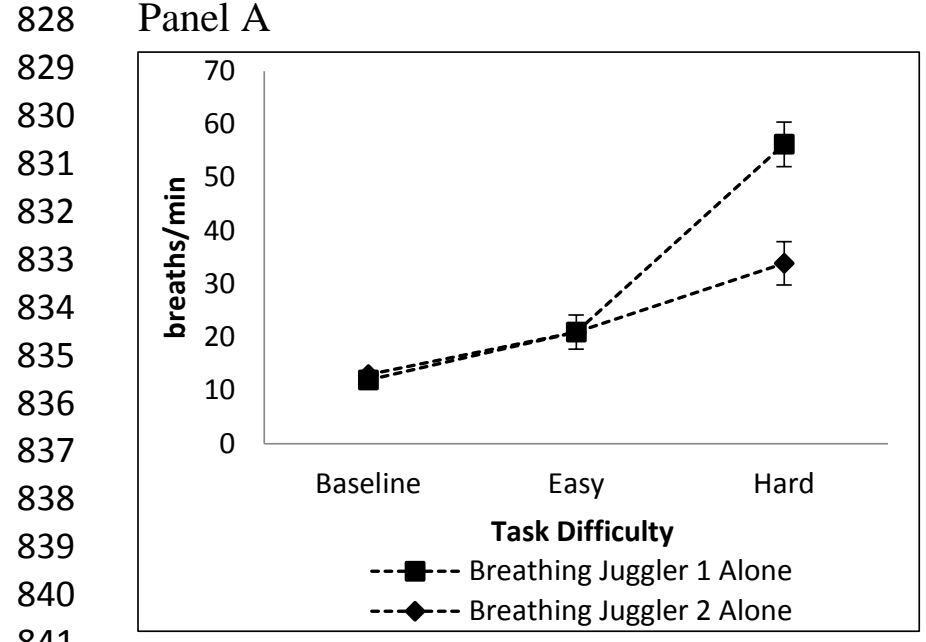

Panel B

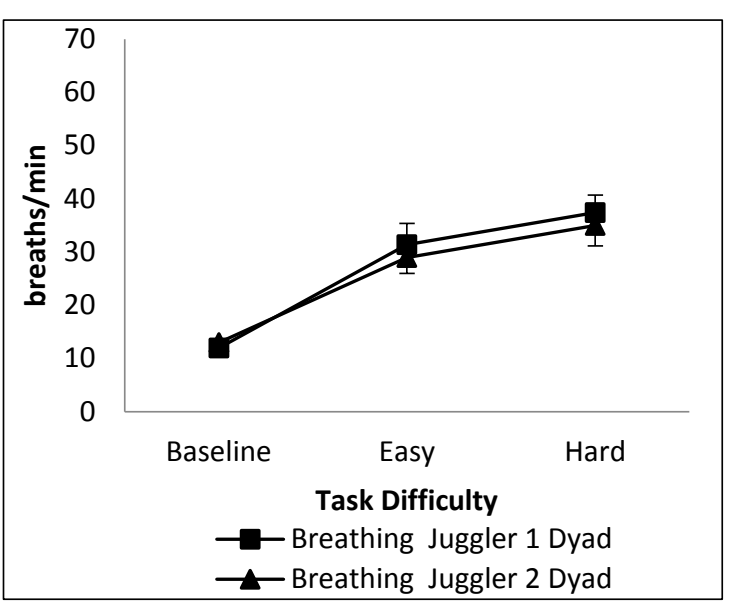

Panel D

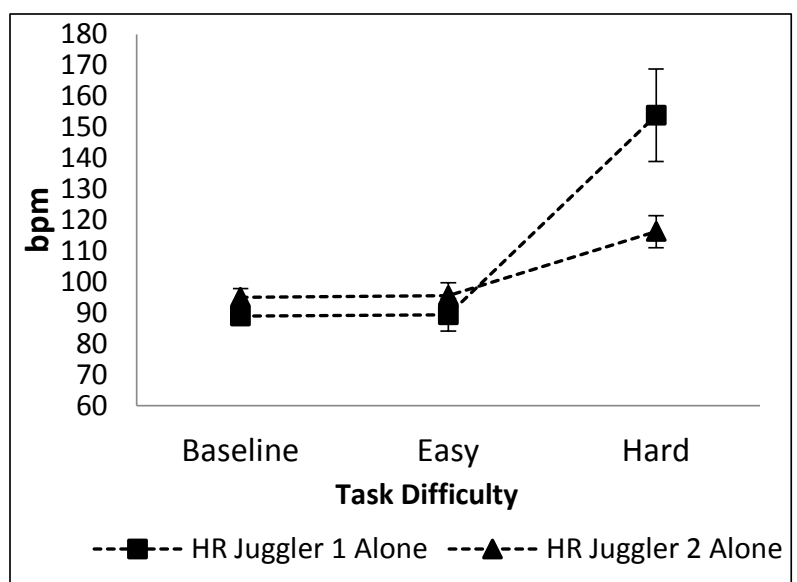

\section{Panel E}

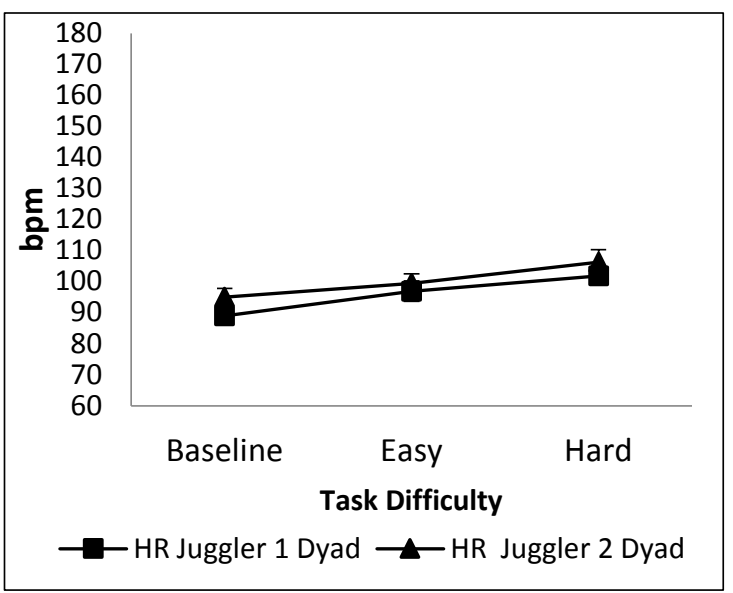

Panel C

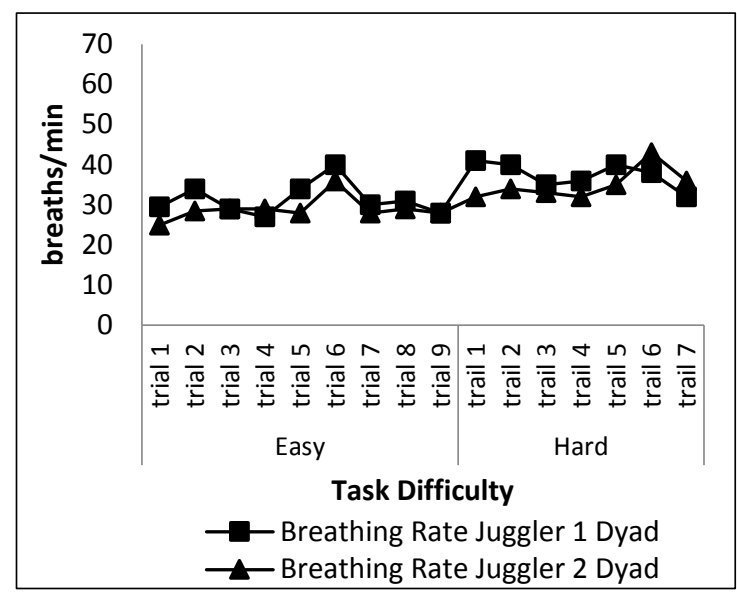

Panel F

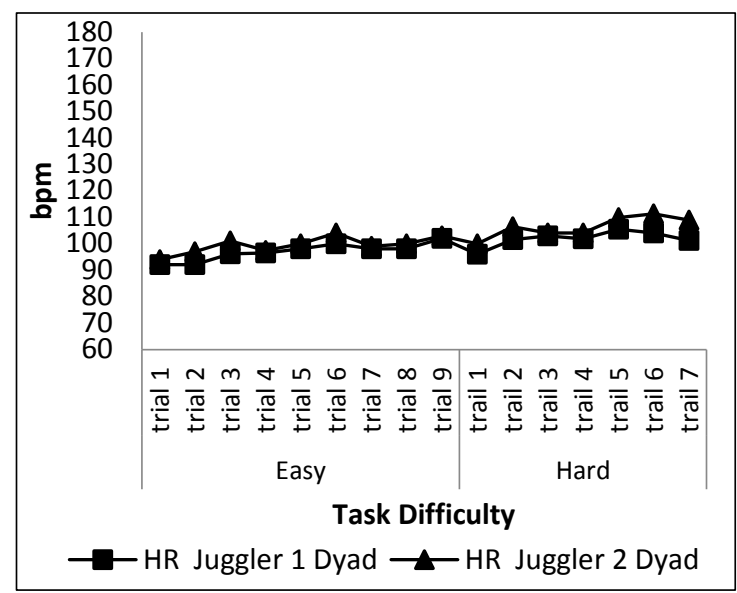

Figure 4. Panel A - J1 and J2 breathing rate (breaths/min) means for individual condition by task difficulty. Panel B - J1 and J2 breathing rate (breaths/min) means for interactive condition by task difficulty. Panel C - Trial per Trial J1 and J2: Breathing rate (breaths/min) means for interactive condition by task difficulty. Panel D - J1 and J2 heart rate (bpm) means for individual condition by task difficulty. Panel E - J1 and J2 heart rate (bpm) means for interactive condition by task difficulty. Panel F - Trial per Trial J1 and J2: heart rate (bpm) means for interactive condition by task difficulty. 